\title{
Domestic Research Progress Analysis of Research Travel Based on CNKI Big Data Quantitative Analysis
}

\author{
Jiuju Zhang ${ }^{1 \#}$,Qing Liu ${ }^{1 \#}$, Zhen Huang ${ }^{2 *}$ \\ ${ }^{I}$ School of Educational Science, Guangxi College of Education, Nanning Guangxi,China \\ ${ }^{2}$ GuangXi Land and Resources Planning and Design Group Co.,LTD.,NanningGuangxi,China \\ *Corresponding author. \\ \#Jiuju Zhang and Qing Liu contributed equally to this work and are co-first authors.
}

\begin{abstract}
With the big data bibliometric analysis function of CNKI, 925 documents were retrieved with "research travel" as the keyword. Visual analysis and index analysis were performed on these documents. In terms of development trend, authors, keywords, fund support and research level, the characteristics of research progress of domestic research travel are summarized.According to the quantitative analysis results of big data, it can be seen that the research on research travel is in the exploratory stage and the research level is single.In the future, researchers need to continuously deepen their research, increase the research of industry guidance, vocational guidance, basic and applied basic research and other types, and constantly enrich the research levels; grasp the hot spots such as geographical practice, core literacy, geographic core literacy, curriculum development, quality education, small research topics, etc, and deepen the research contents of research travel.
\end{abstract}

Keywords:Big data; CNKI; quantitative analysis; research travel

\section{Foreword}

Based on its characteristics of large number, celerity, diversity and reality, big data analysis has been applied in the fields of statistics, market forecasting, model establishment, and soon. Some achievements have been made ${ }^{[1-6]}$.

With the development of big data, visualization technology, scientific metrology and literature metrology, it is no longer a hard task to reveal the interdisciplinary linkages by graphics. In recent years, one of the hot topics in the field of scientific metrology and literature metrology is how to use big data to reveal the relationship between disciplines with visualization graphics on the basis of conveying knowledge accurately and detailedly. ${ }^{[7]}$.

Since 2014, with the publication of relevant national documents, the study on research travels has been popular in China. From the fields of basic education and secondary education, and basic research, to the fields of industry guidance, higher education, and policy research, research types are gradually broadening, and more and more documents are included in China National Knowledge Infrastructure (CNKI). A large amount of data makes it difficult for researchers to analyze. With CNKI big data analysis function, the research progress of domestic research travels was analyzed. It can significantly improve the research efficiency and quality of researches.

\section{II.Analytical Method}

The research data are originated from CNKI database. The searching deadline was September 20, 2019. Since domestic research on research travels started in 2014, the searching time was set from 2014 to 2019 . For the searching database, the Chinese Journal Full-text Database (CJFD), Chinese Doctoral Dissertations Full-text Database, China Master's Theses Full-text Database (CMFD), and China Proceedings of Conference Full-text Database (CPCD) were chosen. The searching keyword was "research travel". 925 documentations were obtained.

ISSN: 0010-8189

(C) CONVERTER 2021 
In terms of development trend, research institute, author, keywords, fund support and research level, quantitative analysis is performed with CNKI metrological visualization analysis function. CNKI visualization analysis function was used to obtain the relevant plots: Data were acquired through point display function, and quantitative analysis is performed with the help of Excel. Relevant plots were obtained by node filtering and clustering analysis, and qualitative analysis was carried out.

\section{Data Processing and Analysis of Result}

\subsection{Number of published papers}

The change in the number of published papers on the same topic reveals the popularity and progress of the scholars' research in this field. It is an important indicator to measure the development of scientific research ${ }^{[8]}$. The analysis of the changes in the number of research documents will contribute to understand the development stage of the research. The documents retrieved from 2014 to 2018 were categorized based on the publication date. The annual variation diagram of literature publication quantity is obtained with the function of index analysis. This diagram comprises two data sets, namely publication quantity and growth rate of publication quantity, such as Fig. 1 .

As shown in Fig.1, It can be seen that the study on "research travel" in China began in 2014, which started relatively late compared with foreign countries. Year 2014-2016 is the starting period of "research travel" ${ }^{[9]}$. In the past three years, the total number of literature published was only 62 with a fluctuation. The annual growth rate was $-56 \%$ in 2015 and $100 \%$ in 2016. After 2016, the number of publications increased significantly, with a yearly growth rate of $782 \%$ in 2017 and 66\% in 2018. In addition, according to CNKI searching statistics, 288 publications on "research travel" were published by September 2019, which has exceeded the total number of publications from the year 2014 to the year 2017. It indicates that the popularity and attraction of "research travel" are gradually increasing. It is not difficult to recognize that the progress of "research travel" in China is closely related to the release of government documents. In 2013, the General Office of the State Council issued the Outline of National Tourism and Leisure (2013-2020). Research travel started in China; in 2016, the Ministry of Education and other 11 departments promulgated Opinions on Promoting the Research Travel of Primary and Secondary School Students, and the popularity of the Research Travel has increased rapidly.

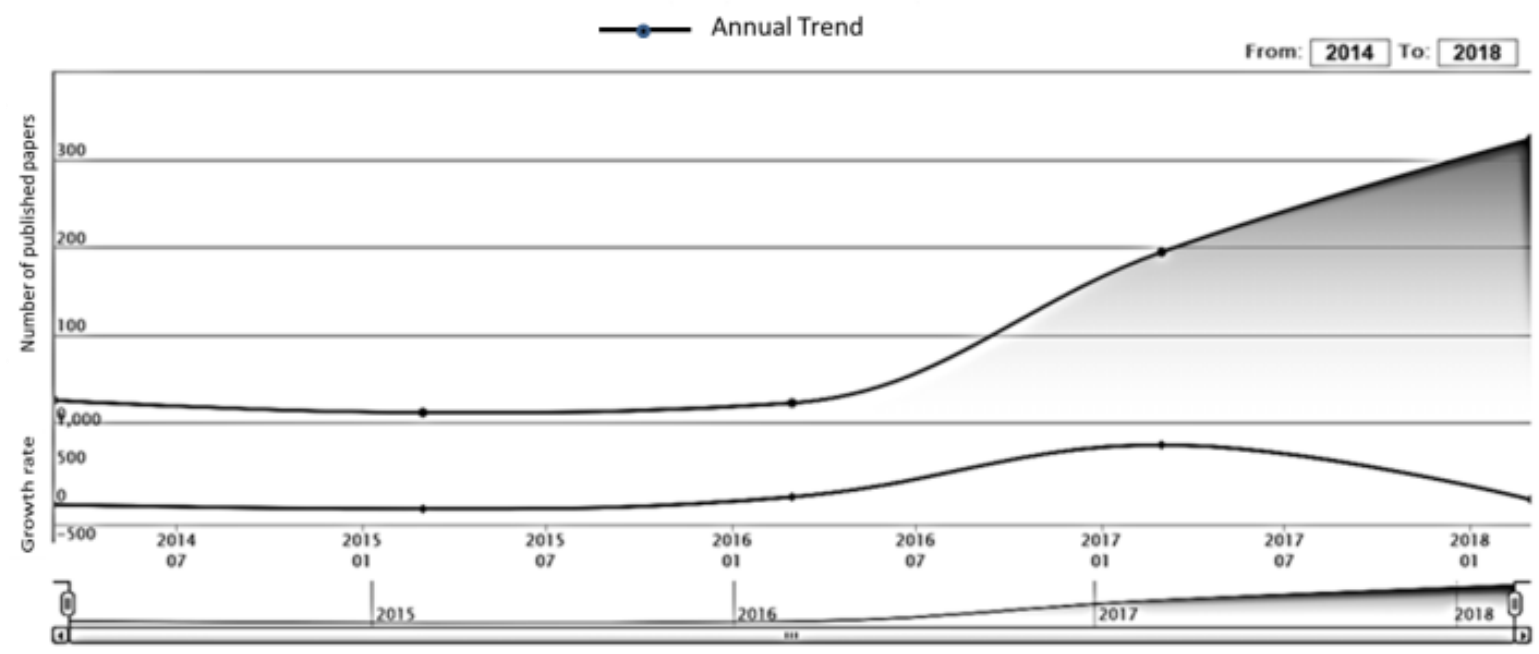

Fig 1:The annual variation of published number(2014-2018)

3.2 Author

ISSN: 0010-8189

(C) CONVERTER 2021 
The retrieved documents were categorized based on the authors, and all the documents of each author were selected. The analysis indexes of each author's total publications were obtained with CNKI metrological visualization analysis, and the static data was achieved for future use.

The number of published papers by researchers in a certain field and the citation of the literature can indicate its activity degree and status in this field. The citation refers to the number that a document has been cited by others after its publication. The higher the citation, the higher the recognition degree of research results in the research field. Therefore, in this paper, the total citations and the Citations per paper are all listed as the influential indexes of the author in the research field.

Statistical analysis of 19 authors whose number of published papers are more than or equal to 3 is performed in terms of research institution, number of published papers, total citations and citations per paper. For details, please refer to Table. 1 Statistics show that all of these 19 authors are from educational institutions, especially universities. There is a little difference in the number of published papers. In terms of influence, YunchaoDing's the citations per paper reaches more than 30, and others are less than 10. It shows that the research is currently in the exploratory stage, and an influential core group of scholars has not yet formed.

Table 1. Statistics Table of authors doing domestic study on research travels ( number of published papers $\geq 3$ )

\begin{tabular}{|c|c|c|c|c|c|}
\hline $\begin{array}{l}\text { Seria } \\
1 \text { No. }\end{array}$ & Author & Research unit & $\begin{array}{c}\text { Number of } \\
\text { published } \\
\text { papers }\end{array}$ & $\begin{array}{c}\text { Total } \\
\text { citations }\end{array}$ & $\begin{array}{l}\text { Citations } \\
\text { per paper }\end{array}$ \\
\hline 1 & Shuqi Yuan & Fujian Normal University & 6 & 16 & 2.67 \\
\hline 2 & YushanDuan & East China Normal University & 5 & 14 & 2.80 \\
\hline 3 & Yunchao Ding & $\begin{array}{c}\text { Fengxian Teaching and Researching Office, } \\
\text { Jiangsu Province }\end{array}$ & 5 & 186 & 31.00 \\
\hline 4 & XiaokaiZuo & $\begin{array}{c}\text { Luoyang No. } 40 \text { Middle School, Henan } \\
\text { Province }\end{array}$ & 4 & 2 & 0.50 \\
\hline 5 & Weiguo Zhou & East China Normal University & 4 & 14 & 3.50 \\
\hline 6 & Hailong Xu & $\begin{array}{c}\text { Nanjing Senior High School of Jiangsu } \\
\text { Province }\end{array}$ & 4 & 5 & 1.25 \\
\hline 7 & FengtaoGuo & East China Normal University & 4 & 14 & 3.50 \\
\hline 8 & Xiliang Ma & $\begin{array}{l}\text { Wuwei City Teachers School for Advanced } \\
\text { Studies, Gansu Province }\end{array}$ & 4 & 13 & 3.25 \\
\hline 9 & Yuan Dong & Chongqing University of Education & 4 & 8 & 2.00 \\
\hline 10 & Chunyan Liu & Jiangxi Normal University & 3 & 2 & 0.67 \\
\hline 11 & MiaoxianXie & South China Normal University & 3 & 6 & 2.00 \\
\hline 12 & Kuo Wang & Hubei University of Science and Technology & 3 & 3 & 1.00 \\
\hline 13 & $\begin{array}{l}\text { Chengshun } \\
\text { Song }\end{array}$ & Hubei University of Science and Technology & 3 & 3 & 1.00 \\
\hline 14 & JijunLan & Shanxi Normal University & 3 & 0 & 0.00 \\
\hline 15 & LinfengZhong & Gannan Normal University & 3 & 24 & 8.00 \\
\hline 16 & Junfang Peng & Fujian Normal University & 3 & 3 & 1.00 \\
\hline 17 & Jiling Liu & Beijing Institute of Education & 3 & 7 & 2.33 \\
\hline 18 & Limin Huang & Hubei University of Science and Technology & 3 & 3 & 1.00 \\
\hline 19 & $\begin{array}{c}\text { Hongzhou } \\
\text { Chen }\end{array}$ & $\begin{array}{c}\text { The Third Experimental Primary School of } \\
\text { Yinan County, Shandong Province }\end{array}$ & 3 & 2 & 0.67 \\
\hline
\end{tabular}


With the application of quantitative analysis, from the time dimension, the 19 authors' cooperation with others is increasing year by year. As shown in Fig.2.

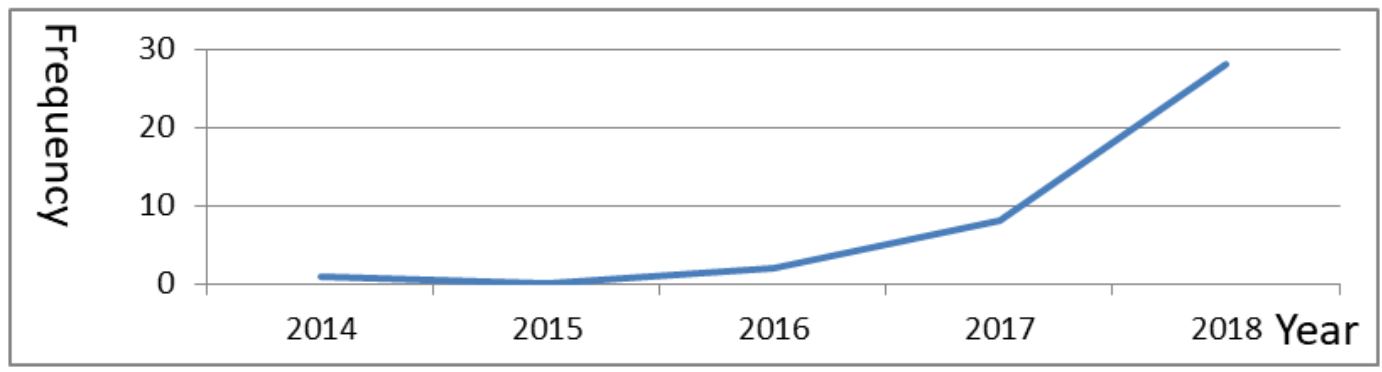

Fig 2: Variation diagram of author's cooperative frequency

Using CNKI visual analysis function, the author collaborative network analysis of the above 19 authors was carried out. By changing the frequency of node filtering, the authors' cooperative network graph is derived. The results are shown in the Fig.3. When the frequency of node filtering is set to 0 , the authors' cooperative network graph is clustered; when set to 1 and 2, it is dotted clustered; and when set to 3 and 4, it becomes dotted gradually; and when set to 5 and 6 , it presents in dot. It indicates that there are lots of research cooperation on study travel, but no network has been formed, so it belongs to small-scale cooperation. Among colleges and universities, cooperation within school and between teachers and students are more common while cooperation between different schools are fewer; in basic education, cooperation mainly occurs in disciplines across units and even across regions; there is also a small amount of cooperation between universities and basic education, which indicates that theoretical research and practical research are gradually integrating.

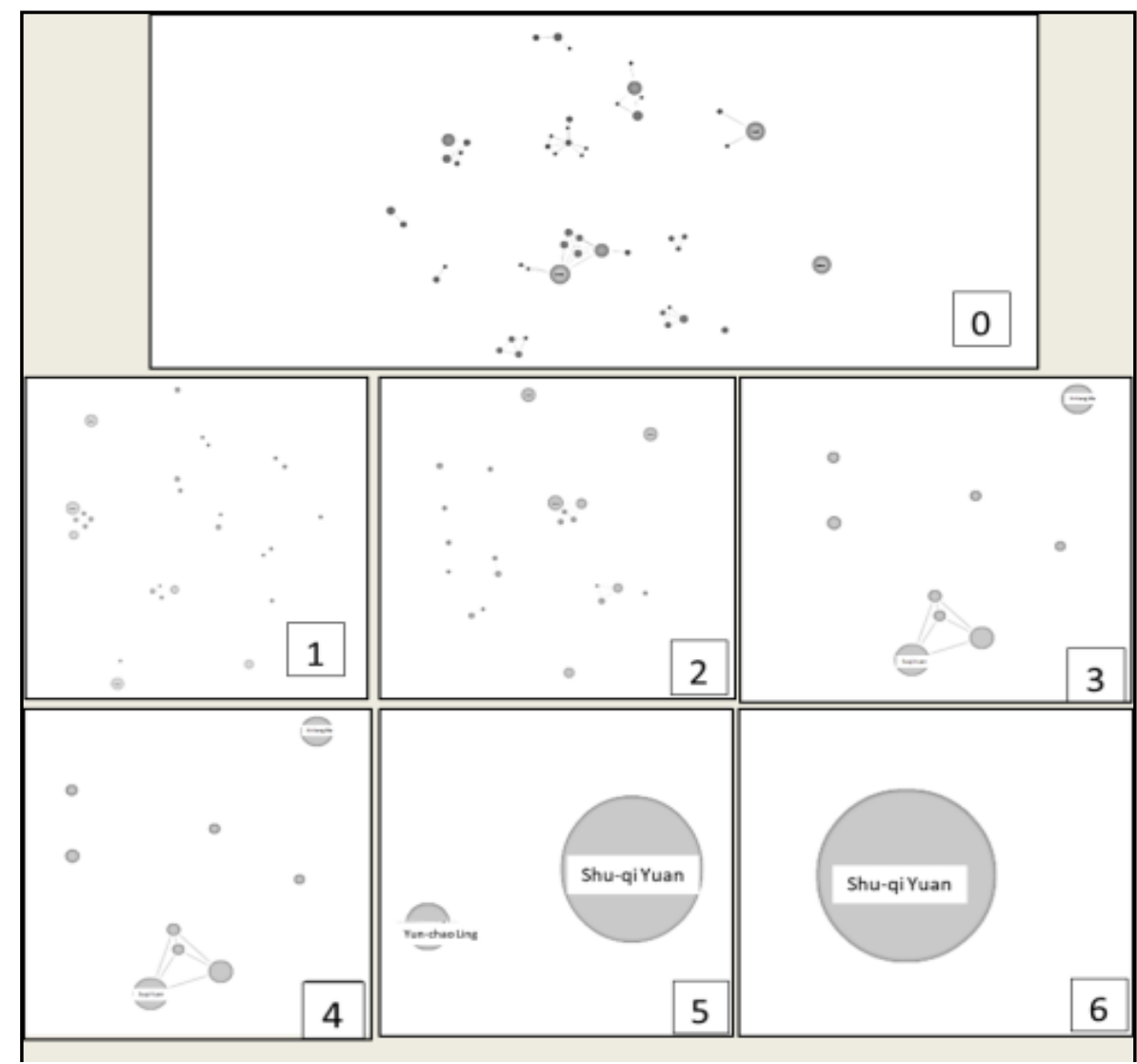

Fig 3: Authors' cooperation network graph(change the frequency of node filtering)

ISSN: 0010-8189

(C) CONVERTER 2021 


\subsection{Keywords}

The key words are the precise summary of the literature ${ }^{[10]}$. By analyzing the frequency of keywords in a research field, we can see the research hotspots and development sequence in this field ${ }^{[8]}$.

With the visibility analysis function of CNKI big data, we get the keyword co-occurrence graph (Fig. 4). Combining with the point display data function, we find that "research travel" appears most frequently, far exceeding other key words, followed by geographical practice, core literacy, geographic core literacy, curriculum development, quality education, small research topics, etc. Other key words radiate around "research travel". After eliminating the high frequency of "research travel", (Fig. 5) the keyword co-occurrence network is extremely simple, which indicates that domestic study on research travel is in an incomplete development period, and other research hotspots related to research travel have just started, with low degree of association. Based on Fig. 5, although the study on research travel is not enough, two hotspots groups have been formed around "research-based learning" and "geographic practical ability".

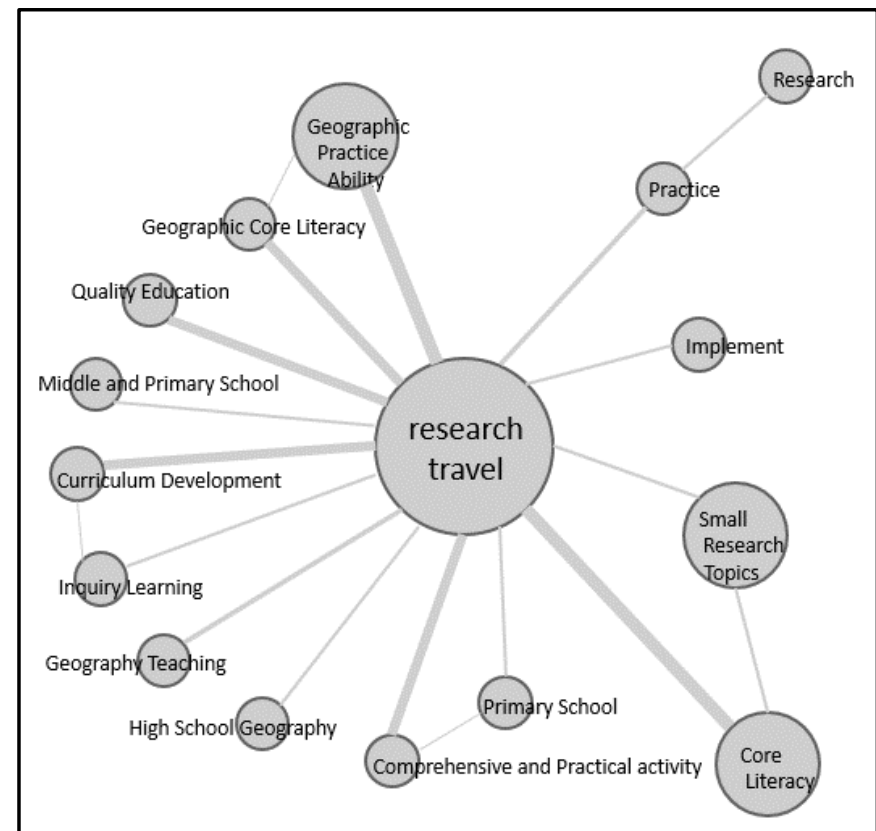

Fig 4: Keywords co-occurrence network

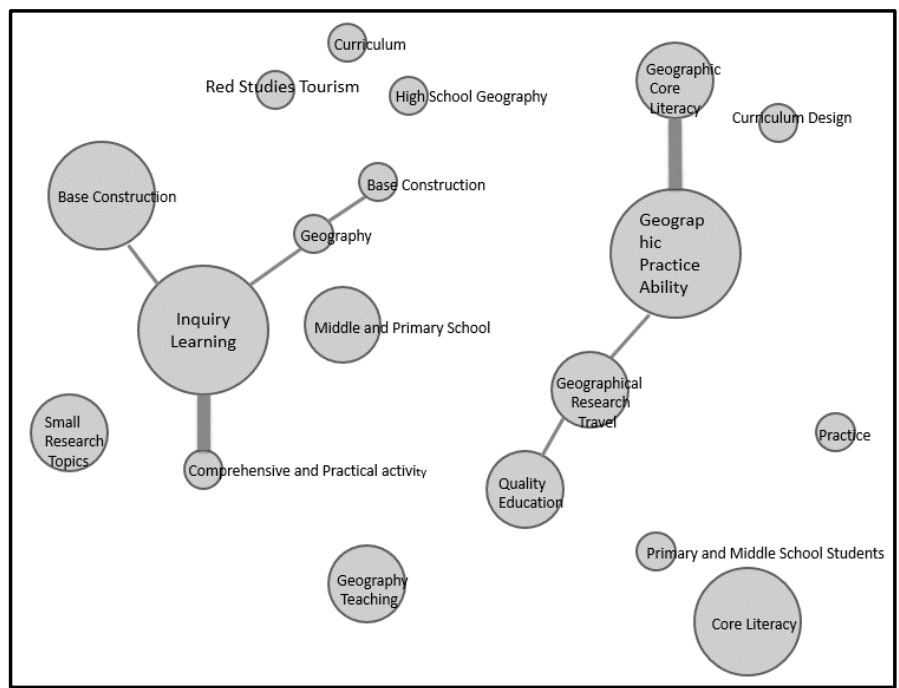

Fig 5: Eliminate" research travel" keywords co-occurrence network 


\subsection{Fund assistance}

In the evaluation of academic journals in recent years, the amount of papers supported by project funds has become an important index in evaluating the academic level and quality of journals. Similarly, the proportion of research papers receiving project funds reflects the academic level and value of research papers in this field, as well as the degree of recognition attached by the state and society ${ }^{[1]}$.

Of the 925 literature retrieved, 22 were funded by research funds at all levels, accounting for only $2.38 \%$ of the total literature (Fig. 6), which reflects that relevant research has not received sufficient attention and funding ${ }^{\text {[12] }}$.

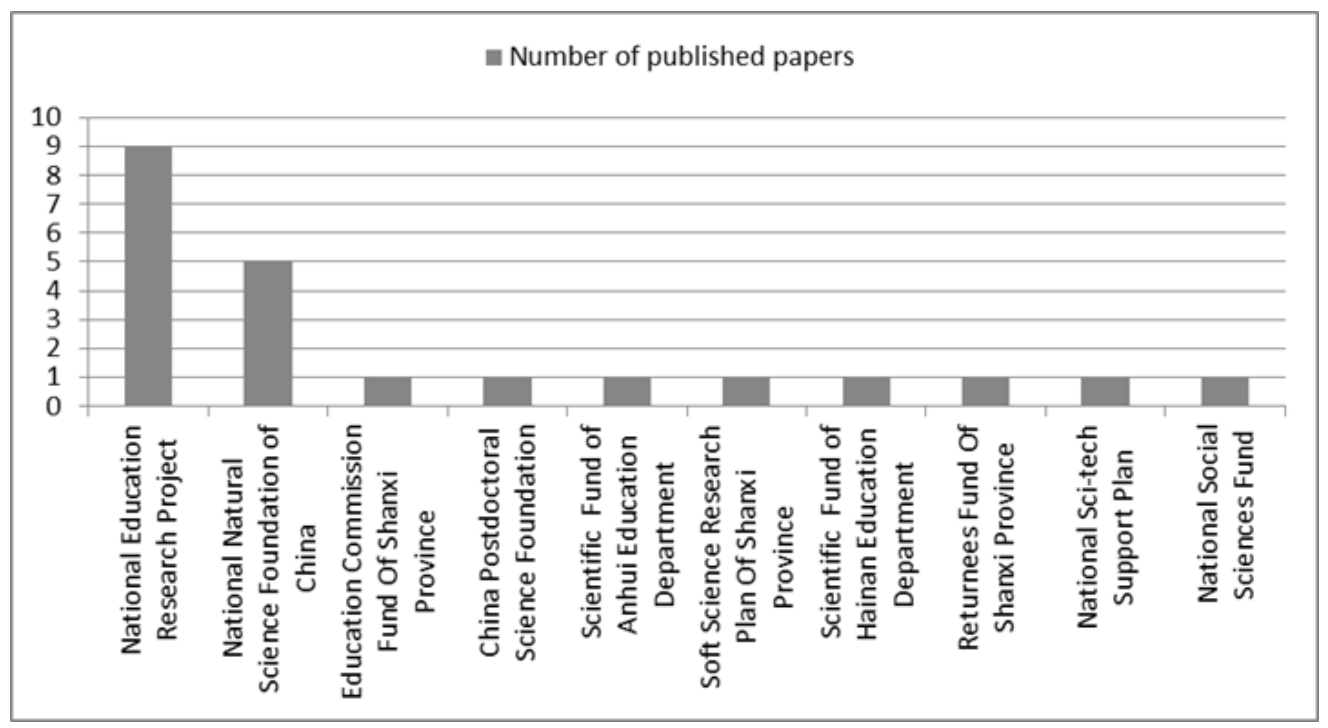

Fig 6: Statistical map of fund subsidies

\subsection{Research level}

Of the 925 literature retrieved, in terms of research level distribution, 427 were basic education and secondary vocational education, accounting for $46.16 \%$. 313 were basic research, accounting for 33.84\%; 68 were industry guidance, accounting for $7.35 \%$; 25 were policy research, accounting for $2.70 \%$; and the proportion of literature in the fields of higher education, vocational guidance (social science), mass culture, basic and applied basic research (natural science) is relatively low,such as Fig. 7. It can be seen that the study of research travel mainly focuses on basic education and secondary vocational education and basic research. 


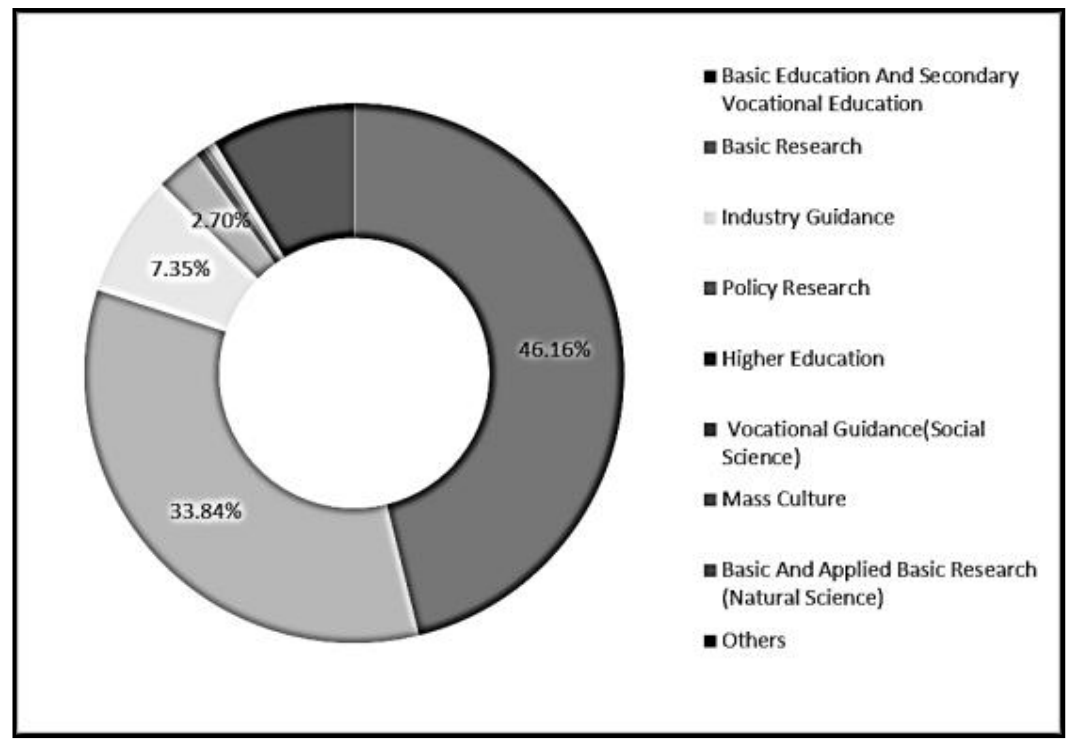

\section{Conclusion}

Fig 7: Research hierarchy distribution

According to the quantitative analysis results of CNKI's big data on "research travel", it can be seen that study on research travel is at the exploratory stage, with increasing attention in the academic circles. Research results are increasing year by year, but there are few high-quality results, and most theoretical researches are not in-depth enough, and relevant researches have not received sufficient attention and fund support. Research travel involves many disciplines, so the phenomenon of cooperation among researchers is obvious, and the frequency of cooperation is increasing. However, the research period is short, no cooperation network is formed, nor an influential core group of authors is organized. The research level is single and the key words are single.

In the future, researchers need to continuously deepen their research, increase the research of industry guidance, vocational guidance, basic and applied basic research and other types, and constantly enrich the research levels;grasp the hot spots such as geographical practice, core literacy, geographic core literacy, curriculum development, quality education, small research topics, etc, and deepen the research contents of research travel; seek for more funds to promote the development of the research, ensure the rapid and stable development of research travel, and continuously form an influential core research group. The study of research travel has strong practical value. Researchers need to increase the integration of theoretical research and practical exploration. Based on the existing theoretical and practical exploration results, they should select high-quality cases to summarize successful experience in time, extract the typical development and implementation model of research travel curriculum, and form the research result promoting double meaning of theory construction and practice reference.

In conclusion, the study of research travel in the exploratory stage has great space for development, which requires scholars to explore the research travel in depth with broad vision and solid professional quality.

\section{Acknowledgment}

This research is financially supported by the Fund of Guangxi Education Department(No.2019KY1684), and Program of Guangxi College of Education (No.B2017003 and No. 2020XJSZ011).

\section{References}

[1] M.J.Mazzei and D.Noble, "Big data dreams: A framework for corporate strategy," Business Horizons, vol. 60, pp. 405-414, 2017. 
[2] W.A.Günther, M.H.R. Mehrizi, M.Huysman and F.Feldberg, Debating big data: a literature review on realizing value from big data," Journal of Strategic Information Systems, vol.26, pp.191-209, 2017.

[3] C.Russell and N.Bennett, "Big data and talent management: using hard data to make the soft stuff easy," Business Horizons, vol.58, pp.237-242, 2015.

[4] J.Manyika, M.Chui, B.Brown, et al., "Big data: the next frontier for innovation, competition, and productivity," McKinsey \& Company,2011, pp.1-136.

[5] C.Chen, "Cite Space 2:detecting and visualizing emerging trends and transient patterns in scientific literature," Journal of the Association for information Science and Technology, vol.57, pp.359-377, 2006.

[6] J.Wang, S.Lou, Q.Ming, "Evaluation of large data analysis function of chinese national knowledge infrastructure based on mountain tourism research in China," International Conference on Information Science and Control Engineering, IEEE Press, 2018, pp. 216-220, doi: 10.1109/ICISCE.2018.00053.

[7] X.Liang, "Literature review on mapping of scientific knowledge," Library Journal, vol.28, pp.58-62, 2009.

[8] Y.Han and J.Liao, "Research progress of laboratory informatization in China: quantitative visualization analysis based on CNKI core periodicals," Technology Innovation and Application, vol.25, pp.13-17, 2019.

[9] X.Li, "Summary and discussion of research travel," Journal of Higher Education, vol.24, pp. 191-193, 2018.

[10] Y.Liao,C.Liu, J.Hua, "Visual analysis of current research situation and hotspots in domestic badminton field," Journal of Anhui Sports Science, vol.40, pp.20-24, 2019.

[11] S.Gong, "Application of bibliometric statistical analysis based on noteexpress: a case study of documents published in information science from 2010 to 2012," Journal of Nantong Vocational \& Technical Shipping College, vol.13, pp. 17-20, 2014.

[12] S.Zheng, J.Li, Y.Zhou, et al., "Bibliometric analysis of sublingual collaterals based on CNKI database,” Journal of Hunan University of Chinese Medicine, vol.39, pp. 222-224, 2019. 